\title{
Change in the right direction for patients
}

\author{
Theodora Bloom executive editor
}

The BMJ

With the NHS facing big challenges, how can its leaders ensure that changes are those that matter most to patients? How can they ensure that everybody pulls in the same direction?

Three overseas recruits to chief executive posts tell The BMJ what the NHS needs most (doi:10.1136/bmj.j1036). There is no shortage of innovative ideas, but implementing them on the wards is hard, especially when an improvement programme may take longer than the tenure of a chief executive.

Bureaucracy and paperwork are everywhere, but does each NHS trust need to produce quite so many weekly statistics for the government? This work, like so much else in the NHS, might be easier to achieve in a fully digitised system that is not fragmented and divided into different layers by successive reorganisations.

Angela Coulter reports (doi:10.1136/bmj.j816) that health ministers from 19 OECD countries have agreed a major programme of work to assess whether health systems deliver what matters most to people, including using a common set of indicators to measure the outcomes that patients judge the most important. We must hope-and check-that the process of measuring these is not too demanding or disruptive to patients, clinicians, or the system as a whole.
Elsewhere, in a review of 95 meta-analyses (doi:10.1136/bmj. j477) Kyrgiou and colleagues find evidence of an association between adiposity and nine cancers (of 36 assessed). An accompanying editorial (doi:10.1136/bmj.j908) concludes that preventing excess weight gain in adults can reduce the risk of these cancers and urges primary care doctors to help to lower this burden. We may need more work to tell us how to achieve this without alienating patients (doi:10.1136/bmj.g6845).

Might the best route to improved outcomes for seriously ill patients be through palliative care introduced earlier, and for more conditions? Scott Murray and colleagues argue (doi:10. 1136/bmj.j878) that such an approach can improve quality of life, avoid unnecessary interventions, and help patients make healthcare choices that chime with their priorities. Such a winning formula may need another name, though, to avoid the current associations with end of life care.

As so many people strive so hard to make positive changes in the NHS and healthcare, David Oliver (doi:10.1136/bmj.j1026) urges politicians, the public, and the press to avoid blaming undeserving or marginal scapegoats for what is not yet achieved, be they "health tourists," "bed blockers," or overstretched hospital doctors and GPs. Everyone needs to pull in the same direction, not dish out blame. 